\title{
Effect of Lateral Substitution on the Electronics and Phase Transitions of Stilbazoles, Benzoic Acids, Phenols, and Hydrogen Bonded Mixtures
}

\author{
Jeremy R. Wolf ${ }^{1,2}$ \\ ${ }^{1}$ Department of Chemistry and Biochemistry, Southern Illinois University Carbondale, Neckers, Room 4409, 1245 Lincoln Drive, \\ Carbondale, IL 62901, USA \\ ${ }^{2}$ Synthesis Department, ABC Laboratories, 7200 E. ABC Lane, Columbia, MO 65202, USA
}

Correspondence should be addressed to Jeremy R. Wolf; wolfchem@hotmail.com

Received 28 June 2015; Revised 30 August 2015; Accepted 1 September 2015

Academic Editor: Mark Humphrey

Copyright (C) 2015 Jeremy R. Wolf. This is an open access article distributed under the Creative Commons Attribution License, which permits unrestricted use, distribution, and reproduction in any medium, provided the original work is properly cited.

\begin{abstract}
The preparation and characterization of laterally substituted 4-alkoxy-stilbazoles, 4-alkoxy-benzoic acids, and 4-alkoxy phenols and hydrogen bonded heterodimeric mixtures of these compounds are reported. Lateral substitution has a minimal effect on the ring electronics of 4-alkoxy benzoic acids and 4-alkoxy phenols; however the ring electronics of stilbazole units is extremely sensitive to lateral substitution. While lateral substitution is an effective technique for lowering the melting points of both hydrogen bonded complexes and their individual components, its effect on the electronics of stilbazoles and steric disruption of both intermolecular hydrogen bonding and molecular packing in the solid state disrupts the formation of liquid crystalline phases in both the individual components and hydrogen bonded complexes.
\end{abstract}

This paper is dedicated to the memory of Dr. Daniel J. Dyer, professor of chemistry at Southern Illinois University, Carbondale

\section{Introduction}

Substituent effects play important roles in a variety of physical phenomena including thermal properties [1], nuclear magnetic resonance shifts [2], and the position of UV absorption bands [3]. Substituents also affect reaction rates and selectivity in a variety of reactions including nucleophilic substitutions and eliminations [4], electrophilic aromatic substitution [5-8], diels-alder reactions [9-12], and organometallic reactions [13-17]. Substituents are also known to affect the acidities of carboxylic acids [18-21] and phenols [22-26]; thus, hydrogen bonding is very sensitive to substituent effects [27-32].

Our research focuses on noncentrosymmetric main chain hydrogen bonded polymers in which monomer units spontaneously self-assemble (via hydrogen bonding) into polymer chain [33-39]. The inherent order in the liquid crystalline phase can aid in polar alignment of these polymers; therefore we are interested in inducing LC phases in our polymers [40]. We have previously synthesized several noncentrosymmetric main chain hydrogen bonded polymers (Table 1 and Scheme 1) which incorporate carboxylic acids hydrogen bond donors and stilbazole hydrogen bond acceptors yet have no lateral substituents $[33,35]$. Unfortunately these polymers have high melting points and low solubilities in organic media, and only one (polymer 5) has a liquid crystalline phase.

Our strategy to lower the melting points, increase solubility, and induce liquid crystallinity in our polymers involves lateral substitution [41-46]. As discussed previously, hydrogen bonding is sensitive to the nature substituents; therefore it is important to study the effect of lateral substitution on the electronics in the donor and acceptor units of our polymers. Unfortunately, all of our laterally substituted polymers 

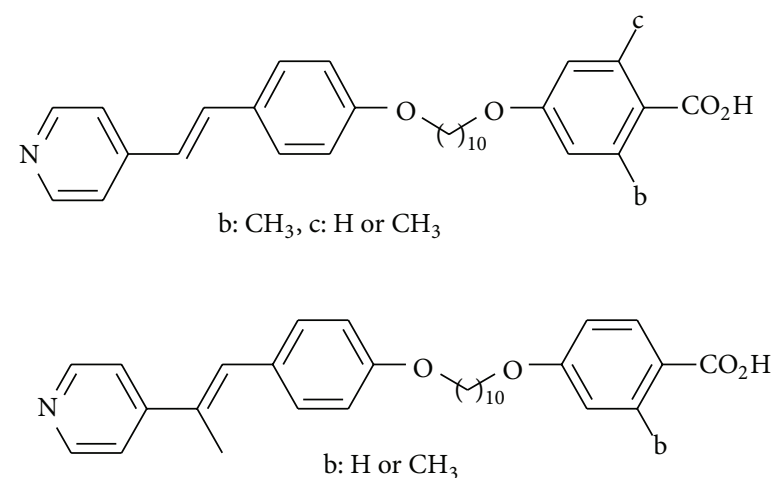

b: $\mathrm{H}$ or $\mathrm{CH}_{3}$

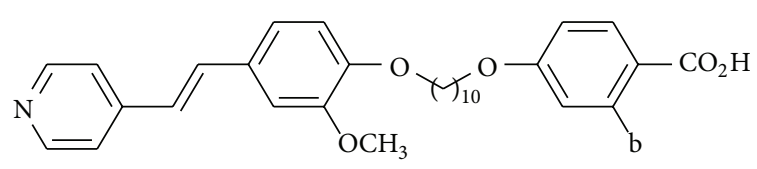

b: $\mathrm{H}$ or $\mathrm{CH}_{3}$

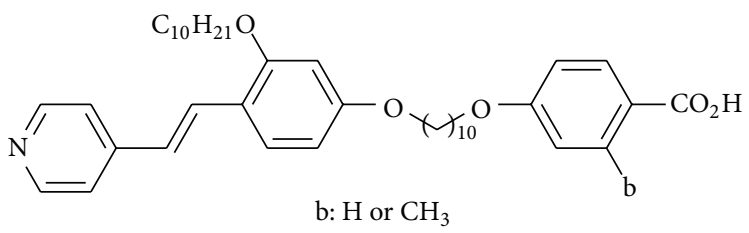

b: $\mathrm{H}$ or $\mathrm{CH}_{3}$

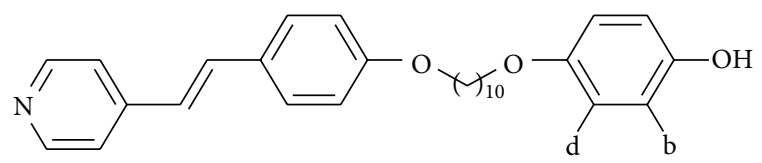

b and d: $\mathrm{H}$ or $\mathrm{CH}_{3}$

FIGURE 1: Monomer units for laterally substituted noncentrosymmetric main chain hydrogen bonded polymers.

TABLE 1: Noncentrosymmetric main chain hydrogen bonded polymers without lateral substituents. See Scheme 1.

\begin{tabular}{lccccc}
\hline Polymer & $\mathrm{X}$ & $n$ & $\mathrm{Y}$ & $\mathrm{Z}$ & m.p. $\left({ }^{\circ} \mathrm{C}\right)$ \\
\hline 1 & $\mathrm{C}$ & 6 & $\mathrm{CO}_{2} \mathrm{H}$ & $\mathrm{H}$ & 279 \\
2 & $\mathrm{C}$ & 10 & $\mathrm{CO}_{2} \mathrm{H}$ & $\mathrm{H}$ & 244 \\
3 & $\mathrm{C}$ & 6 & $\mathrm{H}$ & $\mathrm{CO}_{2} \mathrm{H}$ & 263 \\
4 & $\mathrm{C}$ & 10 & $\mathrm{H}$ & $\mathrm{CO}_{2} \mathrm{H}$ & 186 \\
5 & $\mathrm{~N}$ & 6 & $\mathrm{CO}_{2} \mathrm{H}$ & $\mathrm{H}$ & $237^{*}$ \\
6 & $\mathrm{~N}$ & 10 & $\mathrm{CO}_{2} \mathrm{H}$ & $\mathrm{H}$ & 196 \\
7 & $\mathrm{~N}$ & 6 & $\mathrm{H}$ & $\mathrm{CO}_{2} \mathrm{H}$ & 205 \\
8 & $\mathrm{~N}$ & 10 & $\mathrm{H}$ & $\mathrm{CO}_{2} \mathrm{H}$ & 155 \\
\hline
\end{tabular}

${ }^{*}$ Compound has an enantiotropic smectic A liquid crystalline phase at $220^{\circ} \mathrm{C}$.

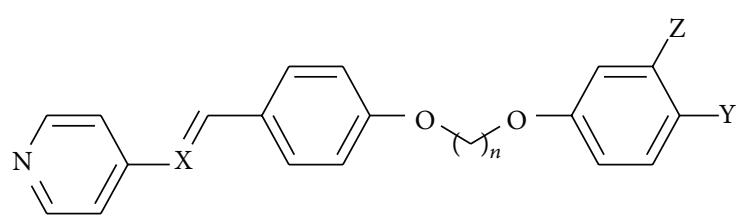

SCHEME 1

(Figure 1) [36] had poor solubilities in organic solvents and diffuse reflectance UV spectra of the polymers had broad peaks (due to Rayleigh scattering [45]) which yielded little useful information.

To circumvent these solubility issues, a series of model compounds (Figure 2) were prepared which mimic the electronics and hydrogen bonding in our polymers. In this paper, we report the synthesis and characterization (electronics and phase transitions) of a series of laterally substituted stilbazoles, benzoic acids, phenols, and hydrogen bonded complexes of these compounds.

\section{Experimental Section}

2.1. Materials. All chemicals were purchased from Fisher, Acros, or Aldrich chemical company and used as received. Chromatography was performed using Sorbent Technology 60 Angstrom, 63-200 $\mu \mathrm{m}$ mesh silica (10940-25). Thin layer chromatography was performed using Whatman flexible plates with $250 \mu \mathrm{m}$ layer of fluorescent silica gel $\left(\mathrm{UV}_{254}\right)$ or EM Science glass TLC plates $\left(60 \mathrm{~F}_{265}\right)$. All final products were dried at appropriate temperatures below their melting or decomposition temperatures in a Napco E-series 5831 vacuum oven prior to analysis.

2.2. Procedure for Making Hydrogen Bonded Heterodimers. 50-100 mg of one component was weighed into a vial and the appropriate amount of the second component (to obtain a 1:1 mol: mol ratio) was weighted into the same vial. The vial was immersed in a silicon oil bath $\left(150^{\circ} \mathrm{C}\right)$ until the contents of the vial were visibly melted. The vial was quickly removed from the oil bath and allowed to cool to room temperature during which time the mixture crystallized. This melt/crystallize procedure was repeated two additional times and the resulting solid was analyzed.

2.3. Equipment. Infrared spectroscopy was performed on a Thermo-Nicolet Nexus 670-FTIR using an Avatar multibounce HATR accessory or KBr salt plates. Differential scanning calorimetry (DSC) was performed on a Mettler Toledo DSC 821e equipped with a Julabo FT 900 cooling unit using heating and cooling rates of $10^{\circ} \mathrm{C} / \mathrm{min}$; all reported transition temperatures are from the second cycle of a DSC scan. All DSC transition temperatures reported are the midpoints of the transitions; enthalpies of the transitions are reported in parentheses following the transition temperature. UV-VIS spectra were acquired on a Varian Cary 100 Bio UV-VIS spectrophotometer. NMR spectra were collected on a Varian VXR 300 wide bore instrument. Polarized optical microscopy was 

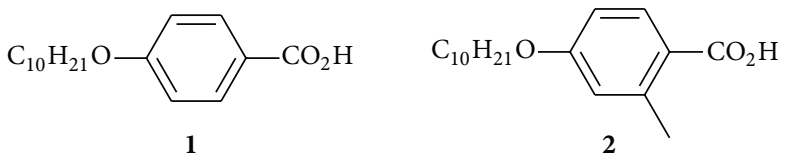

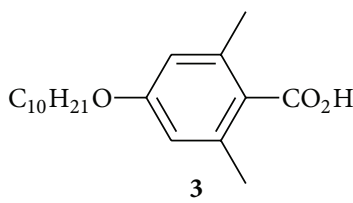

3<smiles>CCCCCCOc1ccc(O)cc1</smiles><smiles>CCCCCCOc1ccc(O)c(C)c1C</smiles>
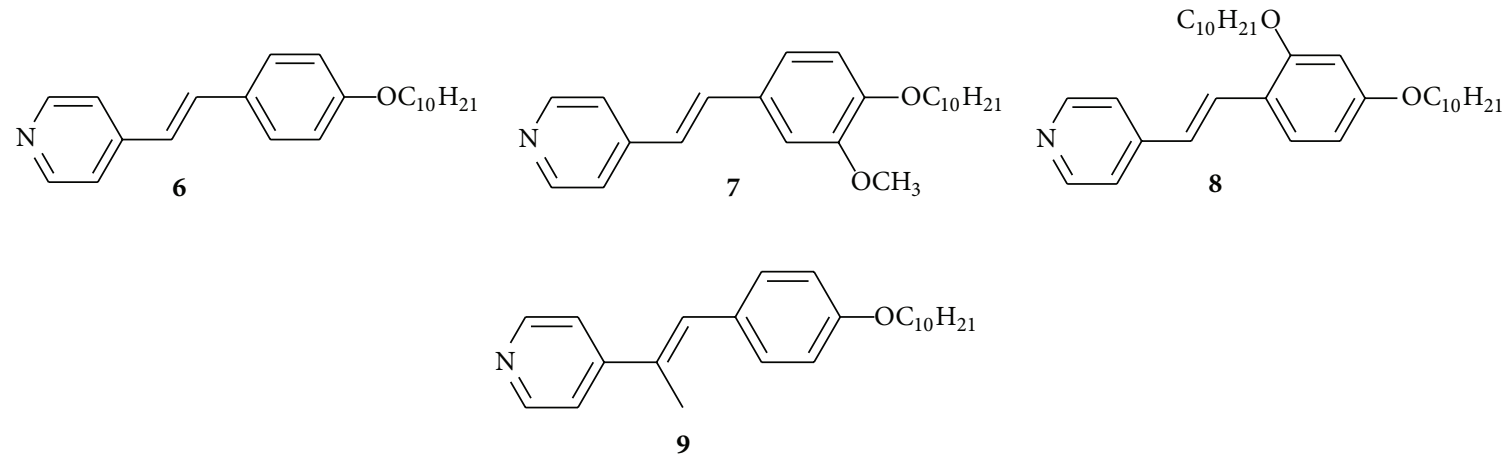

FIGURE 2: Model compounds for studying intermolecular hydrogen bonding.

performed using an Olympus BXP polarizing microscope equipped with an Instec HCS400 heating stage. Heating and cooling rates varied between 1 and $5^{\circ} \mathrm{C} / \mathrm{min}$.

2.4. Molecular Modeling. Molecular modeling was performed using Hyperchem 7.0. Geometry optimization was performed at the PM3 level. All calculations were performed in vacuo with the following termination condition: RMS gradient $=0.01 \mathrm{kcal} / \mathrm{mol}$.

\subsection{Experimental Procedures for Synthesizing Model Compounds}

4-Decyloxy-2-methyl-benzoic Acid (2). This compound was synthesized in two steps. First 4-hydroxy-2-methyl-benzoic acid (0.403 g, $2.41 \mathrm{mmol}), \mathrm{K}_{2} \mathrm{CO}_{3}(1.015 \mathrm{~g}, 8.00 \mathrm{mmol})$, decylbromide $(1.4 \mathrm{~mL}, 6.36 \mathrm{mmol}), \mathrm{NaI}(94 \mathrm{mg}, 0.63 \mathrm{mmol})$, and dry DMF $(20 \mathrm{~mL})$ were combined in an oven-dried round bottomed flask equipped with a condenser and argon purge; this mixture was heated to $120^{\circ} \mathrm{C}$ for 18 hours and then cooled to room temperature. Water $(100 \mathrm{~mL})$ was added and the resulting solution was extracted with EtOAc $(3 \times 10 \mathrm{~mL})$. The combined organic layers were washed with brine $(2 \times 50 \mathrm{~mL})$ and dried over $\mathrm{MgSO}_{4}$. The crude product was purified via column chromatography (80/20 Hex/EtOAc). Evaporation of the solvent afforded $0.577 \mathrm{~g}$ (76\%) of methyl-4-decyloxy-2methyl-benzoate as an impure yellow oil, which was used without further purification: $R_{F}=0.53(90 / 10 \mathrm{Hex} / \mathrm{EtOAc})$; ${ }^{1} \mathrm{H} \mathrm{NMR}\left(300 \mathrm{MHz}, \mathrm{CDCl}_{3}\right) \delta 0.88(\mathrm{t}, J=6.38 \mathrm{~Hz}, 3 \mathrm{H})$, $1.27(\mathrm{~m}, 14 \mathrm{H}), 1.81(\mathrm{~m}, 2 \mathrm{H}), 2.59(\mathrm{~s}, 3 \mathrm{H}), 3.85(\mathrm{~s}, 3 \mathrm{H})$, $3.98(\mathrm{t}, J=6.36 \mathrm{~Hz}, 2 \mathrm{H}), 6.74(\mathrm{~m}, 2 \mathrm{H})$, and $7.92(\mathrm{~d}, J=$ $9.66 \mathrm{~Hz}, 1 \mathrm{H})$. Crude methyl-4-decyloxy-2-methyl-benzoate $(0.577 \mathrm{~g}, 1.87 \mathrm{mmol})$, THF $(30 \mathrm{~mL}), \mathrm{MeOH}(30 \mathrm{~mL}), 5 \mathrm{~N}$ $\mathrm{NaOH}(50 \mathrm{~mL})$, and $\mathrm{KOH}(2.023 \mathrm{~g}, 36.7 \mathrm{mmol})$ were combined in a round bottomed flask equipped with a condenser; this solution was refluxed for 40 hours and then cooled to room temperature. The solution was neutralized using $50 \% \mathrm{HCl}$ and then extracted with EtOAc $(5 \times 50 \mathrm{~mL})$. The combined organic layers were washed with brine $(2 \times 50 \mathrm{~mL})$ and dried over $\mathrm{MgSO}_{4}$. The crude product was purified via column chromatography using graduated elutions from 90/10 to $70 / 30$ (Hex/EtOAc). Evaporation of the solvent afforded $0.316 \mathrm{~g}(57 \%)$ of 2 as a white solid: $R_{F}=0.52(70 / 30$ Hex/EtOAc); ${ }^{1} \mathrm{H}$ NMR $\left(300 \mathrm{MHz}, \mathrm{CDCl}_{3}\right) \delta 0.88(\mathrm{t}, J=$ $6.38 \mathrm{~Hz}, 3 \mathrm{H}), 1.27(\mathrm{~m}, 14 \mathrm{H}), 1.77(\mathrm{~m}, 2 \mathrm{H}), 2.63(\mathrm{~s}, 3 \mathrm{H}), 4.00(\mathrm{t}$, $J=6.53 \mathrm{~Hz}, 2 \mathrm{H}), 6.76(\mathrm{~m}, 2 \mathrm{H})$, and $8.04(\mathrm{~d}, J=9.47 \mathrm{~Hz}, 1 \mathrm{H})$; ${ }^{13} \mathrm{C} \mathrm{NMR}\left(75 \mathrm{MHz}, \mathrm{CDCl}_{3}\right) \delta 14.34,22.91,25.96,26.21,29.34$, 29.54, 29.58, 29.78, 32.12, 35.58, 68.32, 111.68, 117.89, 134.29, 144.43, 162.91, 172.31, and 205.29; IR (ATR) 2913, 2847, 1666, $1605,1563,1282,1246$, and $1155 \mathrm{~cm}^{-1}$; MS (EI+) m/e 292 (152, $134,108,83,69$, and 57).

4-Decyloxy-2,6-dimethyl-benzoic Acid (3). This compound was synthesized in two steps. First, 4-bromo-2,6dimethylphenol (1.004 g, $5.0 \mathrm{mmol}), \mathrm{K}_{2} \mathrm{CO}_{3} \quad(1.524 \mathrm{~g}$, $11.0 \mathrm{mmol}$ ), decylbromide (1.1 mL, $5.3 \mathrm{mmol}$ ), NaI (94 mg, $0.6 \mathrm{mmol})$, and dry DMF $(20 \mathrm{~mL})$ were combined in an oven-dried round bottomed flask equipped with a condenser and argon purge; this mixture was heated to $120^{\circ} \mathrm{C}$ for 18 hours and then cooled to room temperature. Water $(100 \mathrm{~mL})$ was added and the solution was extracted with EtOAc $(3 \times$ $10 \mathrm{~mL}$ ). The combined organic extracts were washed with 
brine $(2 \times 50 \mathrm{~mL})$ and dried over $\mathrm{MgSO}_{4}$. The crude product was purified via column chromatography. Evaporation of the solvent afforded 1.291 g (76\%) of 4-decyloxy-2,6-dimethylbromobenzene as an impure yellow oil, which was used without further purification: $R_{F}=0.80(95 / 5 \mathrm{Hex} / \mathrm{EtOAc})$; ${ }^{1} \mathrm{H}$ NMR $\left(300 \mathrm{MHz}, \mathrm{CDCl}_{3}\right) \delta 0.88(\mathrm{t}, J=6.41 \mathrm{~Hz}, 3 \mathrm{H}), 1.27$ $(\mathrm{m}, 14 \mathrm{H}), 1.75(\mathrm{t}, J=6.87 \mathrm{~Hz}, 2 \mathrm{H}), 2.37(\mathrm{~s}, 6 \mathrm{H}), 3.89(\mathrm{t}, J=$ $6.89 \mathrm{~Hz}, 2 \mathrm{H})$, and $6.64(\mathrm{~s}, 2 \mathrm{H})$. Magnesium turnings $(0.32 \mathrm{~g}$, $13.2 \mathrm{mmol}$ ) were placed in a round bottomed flask equipped with a condenser and argon purge; the flask was flame-dried and cooled to room temperature under argon. Dry $\mathrm{Et}_{2} \mathrm{O}$ $(10 \mathrm{~mL})$ was added to the flask and then a solution of crude 4-decyloxy-2,6-dimethyl-bromobenzene (1.291 g, $3.8 \mathrm{mmol}$ ) in dry $\mathrm{Et}_{2} \mathrm{O}(10 \mathrm{~mL})$ was added to the flask via syringe; this solution was refluxed for 5 hours. The solution was then cooled to room temperature and $\mathrm{CO}_{2}$ was bubbled through the solution (via cannulus) for 1.5 hours; the solution was poured into saturated $\mathrm{NH}_{4} \mathrm{Cl}(200 \mathrm{~mL})$ and the solution was stirred until the magnesium was consumed. The solution was extracted with EtOAc $(5 \times 20 \mathrm{~mL})$ and the combined organic layers were washed with brine $(2 \times 50 \mathrm{~mL})$ and dried over $\mathrm{MgSO}_{4}$. The crude product was purified via column chromatography using graduated elutions from $90 / 10$ to $70 / 30$ (Hex/EtOAc). Evaporation of the solvent afforded $0.561 \mathrm{~g}(48 \%)$ of 3 as a white solid: $R_{F}=0.49(70 / 30$ $\mathrm{Hex} / \mathrm{EtOAc}) ;{ }^{1} \mathrm{H}$ NMR $\left(300 \mathrm{MHz}, \mathrm{CDCl}_{3}\right) \delta 0.88(\mathrm{t}, J=$ $6.75 \mathrm{~Hz}, 3 \mathrm{H}), 1.27(\mathrm{~m}, 14 \mathrm{H}), 1.77(\mathrm{t}, J=6.48 \mathrm{~Hz}, 2 \mathrm{H}), 2.44(\mathrm{~s}$, $6 \mathrm{H}), 3.95(\mathrm{t}, J=6.40 \mathrm{~Hz}, 2 \mathrm{H})$, and $6.59(\mathrm{~s}, 2 \mathrm{H}) ;{ }^{13} \mathrm{C} \mathrm{NMR}$ $\left(75 \mathrm{MHz}, \mathrm{CDCl}_{3}\right) \delta 14.35,21.44,22.33,22.91,26.23,29.40$, $29.55,29.58,29.78,32.12,68.10,114.36,124.16,139.47,160.39$, and 174.02; IR (ATR) 2915, 2851, 1677, 1604, 1318, 1173, and 1058; MS (EI+) m/e 306 (166, 148, 122, 177, and 65).

4-Decyloxy-phenol (4). The synthesis of this compound has been reported in the literature [47].

4-Decyloxy-2,3-dimethyl-phenol (5). This compound was synthesized in two steps. First, of 2-(4-hydroxy-2,3-dimethylphenoxy)-tetrahydropyran $(1.225 \mathrm{~g}, 5.5 \mathrm{mmol}), \mathrm{K}_{2} \mathrm{CO}_{3}$ $(2.058 \mathrm{~g}, 14.9 \mathrm{mmol})$, decylbromide $(1.2 \mathrm{~mL}, 5.75 \mathrm{mmol}), \mathrm{NaI}$ (63 mg, $0.42 \mathrm{mmol}$ ), and dry DMF $(20 \mathrm{~mL})$ were combined in an oven-dried round bottomed flask equipped with a condenser and argon purge; this mixture was heated to $120^{\circ} \mathrm{C}$ for $2 \mathrm{hrs}$ and then cooled to room temperature. Water $(100 \mathrm{~mL})$ was added and the solution was extracted with EtOAc $(2 \times 50 \mathrm{~mL})$. The combined organic layers were washed with brine $(2 \times 50 \mathrm{~mL})$ and dried over $\mathrm{MgSO}_{4}$. The crude product was purified via column chromatography using graduated elutions from neat hexanes to 90/10 (Hex/EtOAc). Evaporation of the solvent afforded $780 \mathrm{mg}$ (39\%) of 2-(4decyloxy-2,3-dimethyl-phenoxy)-tetrahydropyran as an impure yellow oil: $R_{F}=0.81(80 / 20 \mathrm{Hex} / \mathrm{EtOAc}) ;{ }^{1} \mathrm{H} \mathrm{NMR}$ $\left(300 \mathrm{MHz}, \mathrm{CDCl}_{3}\right) \delta 0.88(\mathrm{t}, J=6.34 \mathrm{~Hz}, 3 \mathrm{H}), 1.27(\mathrm{~m}$, $17 \mathrm{H}), 1.76(\mathrm{~m}, 6 \mathrm{H}), 2.16(\mathrm{~s}, 3 \mathrm{H}), 2.19(\mathrm{~s}, 3 \mathrm{H}), 3.58(\mathrm{~m}, 1 \mathrm{H})$, $3.88(\mathrm{~m}, 3 \mathrm{H}), 5.25(\mathrm{t}, J=3.30 \mathrm{~Hz}, 1 \mathrm{H}), 6.62(\mathrm{~d}, J=8.68 \mathrm{~Hz}$, $2 \mathrm{H})$, and $6.88(\mathrm{~d}, J=8.72 \mathrm{~Hz}, 2 \mathrm{H})$. Crude 2 -(4-decyloxy2,3-dimethyl-phenoxy)-tetrahydropyran, THF $(16 \mathrm{~mL})$, and concentrated $\mathrm{HCl}(1 \mathrm{~mL})$ were combined in a round bottomed flask and the resulting solution was stirred at room temperature overnight. Water $(100 \mathrm{~mL})$ was added to the flask, the solution was neutralized with aqueous $\mathrm{NaHCO}_{3}$, and then the solution was extracted with EtOAc $(2 \times 50 \mathrm{~mL})$. The combined organic layers were washed with brine $(2 \times$ $50 \mathrm{~mL}$ ) and dried over $\mathrm{MgSO}_{4}$. Removal of the solvent afforded a pale yellow solid, which was recrystallized from hexanes to afford $347 \mathrm{mg}(58 \%)$ of $\mathbf{5}$ as white solid: $R_{F}=0.30$ (80/20 Hex/EtOAc); ${ }^{1} \mathrm{H}$ NMR $\left(300 \mathrm{MHz}, \mathrm{CDCl}_{3}\right) \delta 0.86(\mathrm{t}$, $J=6.36 \mathrm{~Hz}, 3 \mathrm{H}), 1.25(\mathrm{~m}, 12 \mathrm{H}), 1.45(\mathrm{~m}, 2 \mathrm{H}), 1.74(\mathrm{~m}, 2 \mathrm{H})$, $2.15(\mathrm{~s}, 6 \mathrm{H}), 3.85(\mathrm{t}, J=6.40 \mathrm{~Hz}, 2 \mathrm{H}), 4.33(\mathrm{~s}, 1 \mathrm{H})$, and $6.56(\mathrm{~s}$, $2 \mathrm{H}) ;{ }^{13} \mathrm{C}$ NMR $\left(75 \mathrm{MHz}, \mathrm{CDCl}_{3}\right.$ ) $\delta$; IR (ATR) 3204.8, 2911, 2846, 1610, 1472, 1394, 1247, and $1096 \mathrm{~cm}^{-1}$; MS (EI+) $\mathrm{m} / \mathrm{e}$ $278(151,138,123,85$, and 72$)$.

4-[2-(4-Decyloxy-phenyl)-vinyl]-pyridine (6). This compound was synthesized in two steps. First, 4-methyl-pyridine $(16.115 \mathrm{~g}, 173.4 \mathrm{mmol})$, 4-hydroxy-benzaldehyde (17.964 g, $147.2 \mathrm{mmol})$, and acetic anhydride $(40 \mathrm{~mL})$ were combined in an oven-dried round bottomed flask equipped with a condenser and an argon purge. The resulting mixture was heated to $120^{\circ} \mathrm{C}$ for 48 hours. The solution was cooled to room temperature, $5 \mathrm{~N} \mathrm{NaOH}(200 \mathrm{~mL})$ was added, and the solution was stirred at room temperature overnight. The solution was neutralized with $10 \% \mathrm{HCl}$. Vacuum filtration afforded $6.421 \mathrm{~g}$ (22\%) of 4-(2-pyridin-4-yl-vinyl)-phenol as a pale yellow solid: $R_{F}=0.34\left(90 / 10 \mathrm{CH}_{2} \mathrm{Cl}_{2} / \mathrm{MeOH}\right) ;{ }^{1} \mathrm{H} \mathrm{NMR}(300 \mathrm{MHz}$, DMSO-d $\left.{ }_{6}\right) \delta 6.80(\mathrm{~d}, J=8.22 \mathrm{~Hz}, 2 \mathrm{H}), 7.00(\mathrm{~d}, J=16.06 \mathrm{~Hz}$, $1 \mathrm{H}), 7.48(\mathrm{~m}, 5 \mathrm{H}), 8.49(\mathrm{~d}, J=5.42 \mathrm{~Hz}, 2 \mathrm{H})$, and $9.77(\mathrm{~s}, 1 \mathrm{H})$. 4-(2-Pyridin-4-yl-vinyl)-phenol (1.504 g, $7.6 \mathrm{mmol}), \mathrm{K}_{2} \mathrm{CO}_{3}$ $(2.618 \mathrm{~g}, 18.9 \mathrm{mmol})$, decylbromide $(1.60 \mathrm{~mL}, 7.8 \mathrm{mmol})$, and dry DMF $(20 \mathrm{~mL})$ were combined in an oven-dried round bottomed flask equipped with a condenser and an argon purge; this mixture was heated to $120^{\circ} \mathrm{C}$ for 18 hours and then cooled to room temperature. Water $(100 \mathrm{~mL})$ was added and the solution was extracted with EtOAc $(5 \times 100 \mathrm{~mL})$. The combined organic layers were washed with brine and dried over $\mathrm{MgSO}_{4}$. The crude product was purified via column chromatography using elutions from $60 / 40$ to $50 / 50$ (Hex/EtOAc). Evaporation of the solvent afforded a yellow solid, which was recrystallized twice from hexanes to afford $0.902 \mathrm{~g}(35 \%)$ of $\mathbf{6}$ as a pale yellow solid: $R_{F}=0.37(50 / 50$ Hex/EtOAc); ${ }^{1} \mathrm{H}$ NMR $\left(300 \mathrm{MHz}, \mathrm{CDCl}_{3}\right) \delta 0.88(\mathrm{t}, J=6.36$, $3 \mathrm{H}), 1.27(\mathrm{~m}, 14 \mathrm{H}), 1.79(\mathrm{t}, J=6.83,2 \mathrm{H}), 3.98(\mathrm{t}, J=6.92,2 \mathrm{H})$, $6.90(\mathrm{~m}, 3 \mathrm{H}), 7.26(\mathrm{~d}, J=16.49,1 \mathrm{H}), 7.34(\mathrm{~d}, J=6.34,2 \mathrm{H})$, $7.46(\mathrm{~d}, J=8.86,2 \mathrm{H})$, and $8.54(\mathrm{~d}, J=6.32,2 \mathrm{H}) ;{ }^{13} \mathrm{C} \mathrm{NMR}$ $\left(75 \mathrm{MHz}, \mathrm{CDCl}_{3}\right) \delta 14.09,22.66,26.00,29.20,29.23,29.37$, $29.55,31.87,67.16,68.12,114.82,120.60,123.56,128.35,132.78$, 145.62, 150.11, 154.68, and 159.82; IR (ATR) 2918, 2851, 1590, 1514,1256 , and $1168 \mathrm{~cm}^{-1}$; MS (EI+) $\mathrm{m} / \mathrm{e} 337$ (197, 180, 168, 115, 91, and 62).

4-[2-(4-Decyloxy-3-methoxy-phenyl)-vinyl]-pyridine (7). This compound was synthesized in two steps. First, 2-methoxy-4(2-pyridin-4-yl-vinyl)-phenol was synthesized in 50\% yield from 4-methyl-pyridine ( $22 \mathrm{~mL}, 226 \mathrm{mmol}$ ), vanillin (9.993 g, $65.7 \mathrm{mmol})$, and acetic anhydride $(30 \mathrm{~mL})$ using the procedure described in the synthesis of 4-(2-pyridin-4-yl-vinyl)phenol: $R_{F}=0.60(80 / 20 \mathrm{EtOAc} / \mathrm{MeOH}) ;{ }^{1} \mathrm{H}$ NMR $\left(300 \mathrm{MHz}, \mathrm{DMSO}_{6} \mathrm{~d}_{6}\right) \delta 3.82(\mathrm{~s}, 3 \mathrm{H}), 6.85(\mathrm{~d}, J=8.54 \mathrm{~Hz}$, 
$1 \mathrm{H}), 7.10(\mathrm{t}, J=5.46 \mathrm{~Hz}, 2 \mathrm{H}), 7.33(\mathrm{~s}, 1 \mathrm{H}), 7.59$ (m, 3H), 8.55 $(\mathrm{d}, J=5.92 \mathrm{~Hz}, 2 \mathrm{H})$, and $9.31(\mathrm{~s}, 1 \mathrm{H})$. The title compound was synthesized from 2-methoxy-4-(2-pyridin-4-yl-vinyl)phenol (1.999 g, $9.5 \mathrm{mmol}), \mathrm{K}_{2} \mathrm{CO}_{3}(3.989 \mathrm{~g}, 28.9 \mathrm{mmol})$, and decylbromide $(2.0 \mathrm{~mL}, 10.2 \mathrm{mmol})$ using the procedure described in the synthesis of 14. Column chromatography was performed using graduated elutions from $65 / 35$ to $50 / 50$ (Hex/EtOAc); evaporation of the solvent afforded an impure yellow powder. This solid was recrystallized from hexanes to afford $1.411 \mathrm{~g}(40 \%)$ of 7 as a tan powder: $R_{F}=0.35$ (50/50 Hex/EtOAc); ${ }^{1} \mathrm{H} \mathrm{NMR}\left(300 \mathrm{MHz}, \mathrm{CDCl}_{3}\right) \delta 0.88(\mathrm{t}, J=$ $6.28 \mathrm{~Hz}, 3 \mathrm{H}), 1.38(\mathrm{~m}, 14 \mathrm{H}), 1.86(\mathrm{t}, J=6.80 \mathrm{~Hz}, 2 \mathrm{H}), 3.93(\mathrm{~s}$, $3 \mathrm{H}), 4.04(\mathrm{t}, J=6.96 \mathrm{~Hz}, 2 \mathrm{H}), 6.86(\mathrm{~m}, 2 \mathrm{H}), 7.07(\mathrm{~d}, J=7.32 \mathrm{~Hz}$, $2 \mathrm{H}), 7.26(\mathrm{~d}, J=16.16 \mathrm{~Hz}, 1 \mathrm{H}), 7.32(\mathrm{~d}, J=6.30 \mathrm{~Hz}, 2 \mathrm{H})$, and $8.54(\mathrm{~d}, J=5.86 \mathrm{~Hz}, 2 \mathrm{H}) ;{ }^{13} \mathrm{C} \mathrm{NMR}\left(75 \mathrm{MHz}, \mathrm{CDCl}_{3}\right) \delta$; IR (ATR) 2935, 2919, 2849, 1584, 1514, 1267, and $1016 \mathrm{~cm}^{-1}$; MS (EI+) $m / e ~ 367(346,315,227,178,107$, and 63).

4-[2-(2,4-Bis-decyloxy-phenyl)-vinyl]-pyridine (8). This compound was synthesized in two steps. First, 2,4dihydroxybenzaldehyde $\quad(5.033 \mathrm{~g}, \quad 36.4 \mathrm{mmol}), \quad \mathrm{K}_{2} \mathrm{CO}_{3}$ (15.238 g, $110.3 \mathrm{mmol})$, decylbromide $(21.0 \mathrm{~mL}, 102.5 \mathrm{mmol})$, and dry DMF $(40 \mathrm{~mL})$ were combined in an oven-dried round bottomed flask equipped with a condenser and argon purge; this mixture was heated to $120^{\circ} \mathrm{C}$ overnight and then cooled to room temperature. Water $(100 \mathrm{~mL})$ was added and the solution was extracted with EtOAc $(5 \times 50 \mathrm{~mL})$. The combined organic layers were washed with brine and dried over $\mathrm{MgSO}_{4}$. The crude product was purified via column chromatography using graduated elutions from neat hexanes to 95/5 (Hex/EtOAc). Evaporation of the solvent afforded $13.426 \mathrm{~g}$ (89\%) of 2,4-bis-decyloxy-benzaldehyde as an impure orange oil, which was used without further purification: $R_{F}=0.50\left(95 / 5 \mathrm{Hex} /\right.$ EtOAc); ${ }^{1} \mathrm{H} \mathrm{NMR}$ $\left(300 \mathrm{MHz}, \mathrm{CDCl}_{3}\right) \delta 0.88(\mathrm{t}, J=6.65 \mathrm{~Hz}, 3 \mathrm{H}), 1.42(\mathrm{~m}, 28 \mathrm{H})$, $1.81(\mathrm{~m}, 4 \mathrm{H}), 4.03(\mathrm{~m}, 4 \mathrm{H}), 6.42(\mathrm{~d}, J=2.22 \mathrm{~Hz}, 1 \mathrm{H}), 6.50(\mathrm{dd}$, $J=2.25 \mathrm{~Hz}, 1 \mathrm{H}), 7.79(\mathrm{~d}, J=8.88 \mathrm{~Hz}, 1 \mathrm{H})$, and $10.32(\mathrm{~s}, 1 \mathrm{H})$. Crude 2,4-bis-decyloxy-benzaldehyde (13.4 g, $32.0 \mathrm{mmol})$, 4picoline $(5.0 \mathrm{~mL}, 51.0 \mathrm{mmol})$, and acetic anhydride $(20 \mathrm{~mL})$ were combined in an oven-dried round bottomed flask equipped with a condenser and argon purge; this solution was heated to $150^{\circ} \mathrm{C}$ for 48 hours and cooled to room temperature. Water $(50 \mathrm{~mL})$ was added and the resulting solution was extracted with EtOAc $(10 \times 50 \mathrm{~mL})$. The combined organic layers were washed with brine $(2 \times 50 \mathrm{~mL})$ and dried over $\mathrm{MgSO}_{4}$. The crude product was purified via column chromatography (twice) using graduated elutions from neat hexanes to 80/20 (Hex/EtOAc). Evaporation of the solvent afforded $1.024 \mathrm{~g}(7 \%)$ of $\mathbf{8}$ as a brown oil: $R_{F}=0.28$ (80/20 Hex/EtOAc); ${ }^{1} \mathrm{H}$ NMR $\left(300 \mathrm{MHz}, \mathrm{CDCl}_{3}\right) \delta 0.86$ $(\mathrm{m}, 3 \mathrm{H}), 1.37(\mathrm{~m}, 31 \mathrm{H}), 1.83(\mathrm{~m}, 4 \mathrm{H}), 3.98(\mathrm{~m}, 4 \mathrm{H}), 6.47(\mathrm{~m}$, $2 \mathrm{H}), 6.95(\mathrm{~d}, J=17.05 \mathrm{~Hz}, 1 \mathrm{H}), 7.30(\mathrm{~d}, J=4.85 \mathrm{~Hz}, 1 \mathrm{H}), 7.54$ $(\mathrm{m}, 4 \mathrm{H})$, and $8.50(\mathrm{~d}, J=4.93 \mathrm{~Hz}, 2 \mathrm{H}) ;{ }^{13} \mathrm{C} \mathrm{NMR}(75 \mathrm{MHz}$, $\mathrm{CDCl}_{3}$ ) $\delta$; IR (ATR) 2923, 2854, 1591, 1503, 1293, and 1181; MS (EI+) m/e 493 (446, 418, 353, 276, 261, 213, 137, 121, 106, and 83).

4-[2-(4-Decyloxy-phenyl)-1-methyl-vinyl]-pyridine (9). This compound was synthesized in two steps. First, 4-(2-pyridin- 4-yl-propenyl)-phenol was synthesized in 58\% yield from 4ethyl-pyridine ( $2 \mathrm{~mL}, 18.5 \mathrm{mmol})$, 4-hydroxy-benzaldehyde $(1.800 \mathrm{~g}, 14.7 \mathrm{mmol})$, and acetic acid $(10 \mathrm{~mL})$ using procedure described in the synthesis of 4-(2-pyridin-4-yl-vinyl)-phenol: $R_{F}=0.35\left(90 / 10 \mathrm{CH}_{2} \mathrm{Cl}_{2} / \mathrm{MeOH}\right) ;{ }^{1} \mathrm{H} \mathrm{NMR}(300 \mathrm{MHz}$, $\left.\mathrm{DMSO}_{-} \mathrm{d}_{6}\right) \delta 2.21(\mathrm{~s}, 3 \mathrm{H}), 6.80(\mathrm{~d}, J=8.52 \mathrm{~Hz}, 2 \mathrm{H}), 7.06$ (s, $1 \mathrm{H}), 7.28(\mathrm{~d}, J=8.50 \mathrm{~Hz}, 2 \mathrm{H}), 7.52(\mathrm{~d}, J=5.65 \mathrm{~Hz}, 2 \mathrm{H})$, and $8.52(\mathrm{~d}, J=5.92 \mathrm{~Hz}, 2 \mathrm{H}) ;{ }^{13} \mathrm{C}$ NMR $(75 \mathrm{MHz}, \mathrm{DMSO}-$ $\left.\mathrm{d}_{6}\right) \delta 16.21,115.22,120.21,127.80,130.16,130.83,131.22,149.40$, 149.72, and 156.84; IR (ATR) 2989, 2872, 1598, 1580, 1501, 1284, 1218, and $1009 \mathrm{~cm}^{-1}$; MS (EI+) m/e $211(196,182,105$, and 77). The title compound was synthesized from 4-(2pyridin-4-yl-propenyl)-phenol (1.231 g, $5.8 \mathrm{mmol}), \mathrm{K}_{2} \mathrm{CO}_{3}$ (2.000 g, $14.5 \mathrm{mmol})$, and decylbromide $(1.45 \mathrm{~mL}, 6.9 \mathrm{mmol})$ using the procedure described in the synthesis of 9 . Column chromatography was performed using graduated elutions from 80/20 to 50/50 (Hex/EtOAc); evaporation of the solvent afforded an impure yellow solid. The solid so obtained was recrystallized (twice) from 95/5 hexane/toluene to afford $0.778 \mathrm{~g}(40 \%)$ of compound 9 as a $\tan$ solid: $R_{F}=0.38$ (60/40 Hex/EtOAc); ${ }^{1} \mathrm{H}$ NMR $\left(300 \mathrm{MHz}, \mathrm{CDCl}_{3}\right) \delta 0.86(\mathrm{t}$, $J=6.73 \mathrm{~Hz}, 3 \mathrm{H}), 1.40(\mathrm{~m}, 14 \mathrm{H}), 1.78(\mathrm{~m}, 2 \mathrm{H}), 2.25(\mathrm{~s}, 3 \mathrm{H})$, $3.97(\mathrm{t}, J=6.15 \mathrm{~Hz}, 2 \mathrm{H}), 6.92(\mathrm{~m}, 2 \mathrm{H}), 7.26(\mathrm{~s}, 1 \mathrm{H}), 7.29(\mathrm{~d}$, $J=8.70 \mathrm{~Hz}, 2 \mathrm{H}), 7.37(\mathrm{~d}, J=6.49 \mathrm{~Hz}, 2 \mathrm{H})$, and $8.55(\mathrm{~d}, J=$ $4.30 \mathrm{~Hz}, 2 \mathrm{H}$ ); IR (ATR) 2918, 2850, 1589, 1509, 1409, 1254, and $1177 \mathrm{~cm}^{-1}$; MS (EI+) m/e 351 (211, 196, 167, 107, and 69).

\section{Results and Discussion}

3.1. Effect of Lateral Substitution on the Electronics of Model Compounds. UV/VIS spectra of acids 1-3 are shown in Figure 3. The $\lambda_{\max }$ of $\mathbf{2}$ is similar to that of $\mathbf{3}$ indicating that placing a single methyl group ortho to the acid functionality does not significantly alter the electronics of the molecule. Placing two methyl groups ortho to the acid functionality, however, significantly alters the electronics of the molecule as evident by the blue shift of the $\lambda_{\max }$ of 3 relative to 1 and 2. Molecular modeling (Figure 4) indicates that the $\mathrm{C}=\mathrm{O}$ and benzene rings in acids $\mathbf{1}$ and $\mathbf{2}$ are nearly coplanar with torsion angles of $2.6 \times 10^{-5}$ and $1.5 \times 10^{-6}$ degrees, respectively, while the $\mathrm{C}=\mathrm{O}$ in compound 3 has a torsion angle of 27.8 degrees with respect to the benzene ring. The torsion angle in compound 3 is similar to literature values for the torsion angles of 2,6-dimethylbenzoic acids [48-51].

The UV-VIS spectra of phenols 4 and 5 are shown in Figure 5. The $\lambda_{\max }$ values for these phenols are nearly identical suggesting that methyl lateral substituents have a minimal effect on the electronics of phenols. Molecular modeling (Figure 6) confirms that the $\mathrm{O}-\mathrm{H}$ and benzene ring in 4 and 5 are nearly coplanar with torsion angles of 0.2 and $1.1^{\circ}$, respectively.

UV-VIS spectra of stilbazoles 6-9 are shown in Figure 7. The red shifts of the $\lambda_{\max }$ of compounds 7 and 8 relative to that of $\mathbf{6}$ can be attributed to additional electron density donated to the rings from the additional alkoxy substituents per Dewar's rules [52]. The $\lambda_{\max }$ of $\mathbf{9}$ is significantly blue shifted with respect to that of compounds 6-8 suggesting less electron delocalization in $\mathbf{9}$ relative to 6-8. Molecular 

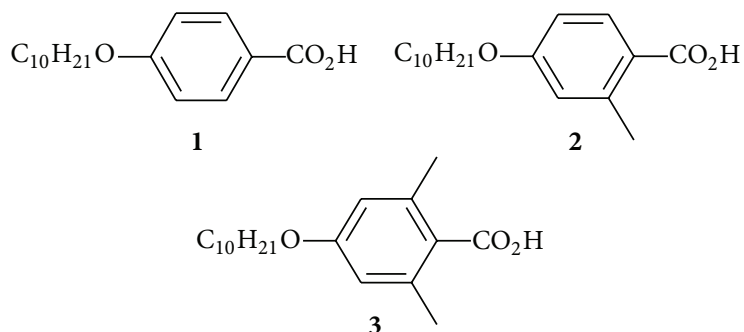

3

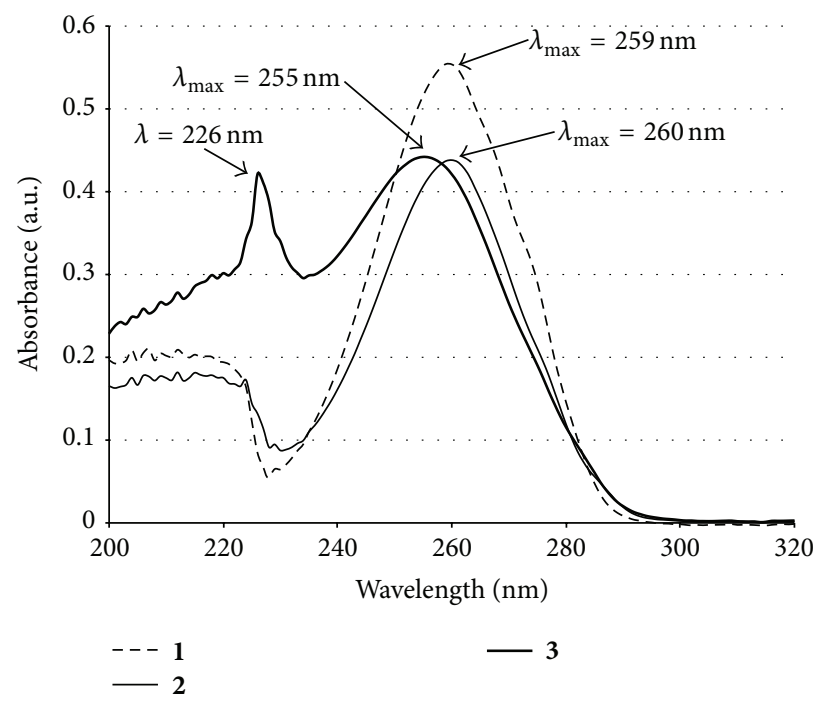

FIGURE 3: UV-VIS spectra of benzoic acids 1-3 in dichloromethane.
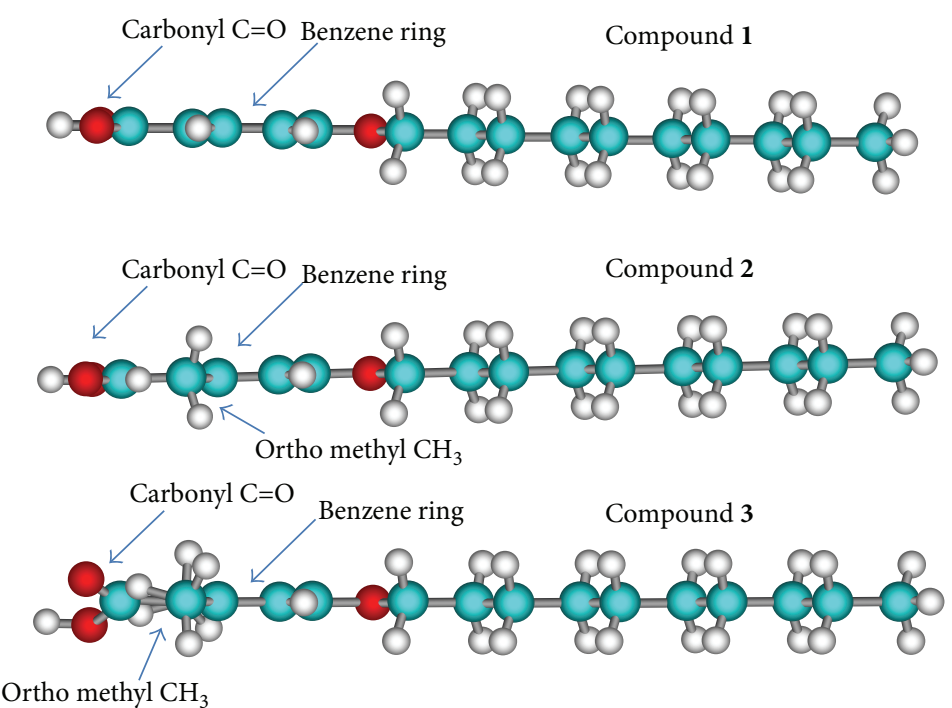

FIGURE 4: Geometry optimized structures of compounds 1-3.

modeling (Figure 8) indicates that the pyridine, alkene, and benzene rings in stilbazoles $\mathbf{6} \mathbf{- 8}$ are coplanar while the methyl group on the alkene of stilbazole $\mathbf{9}$ causes ring twisting with a torsion angle of $28^{\circ}$ between the pyridine and benzene ring.

3.2. Lateral Substitution Effects on Phase Transitions. The phase transitions of compounds 1-9 are shown in Figure 9.
Placing a methyl group ortho to the acid functionality on compound $\mathbf{1}$ (i.e., compound 2 ) results in a significant melting point depression and the loss of the smectic liquid crystalline (LC) phases present in 1 [53-55]. Molecular modeling (Figure 10) indicates similar hydrogen bond strengths for head-to-head hydrogen bonding in compounds 1 (calculated hydrogen bond length $=1.7681 \AA$ ) and 2 (calculated hydrogen 

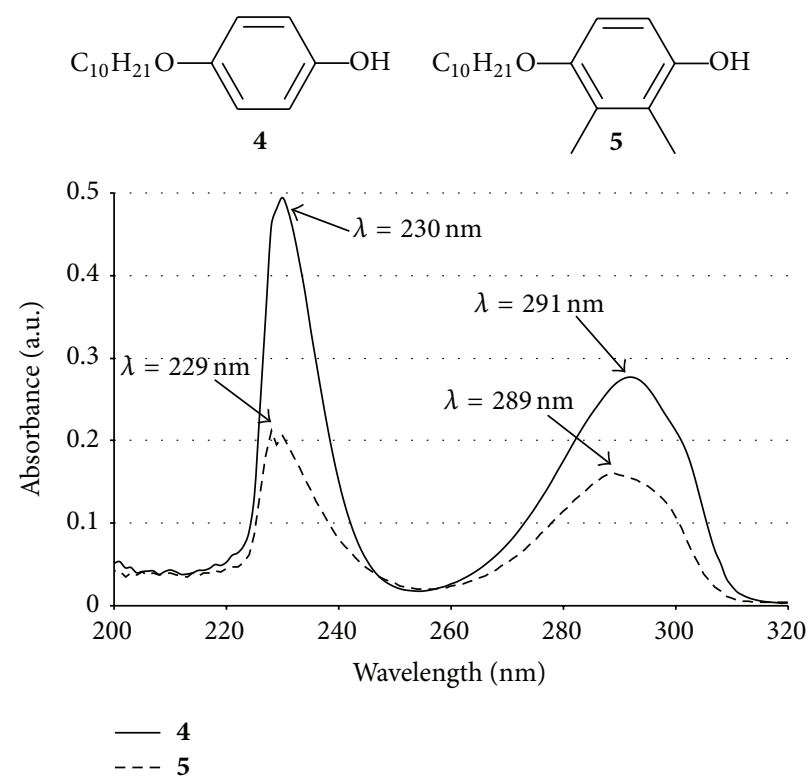

FIgURE 5: UV-VIS spectra of phenols 4 and $\mathbf{5}$ in dichloromethane.
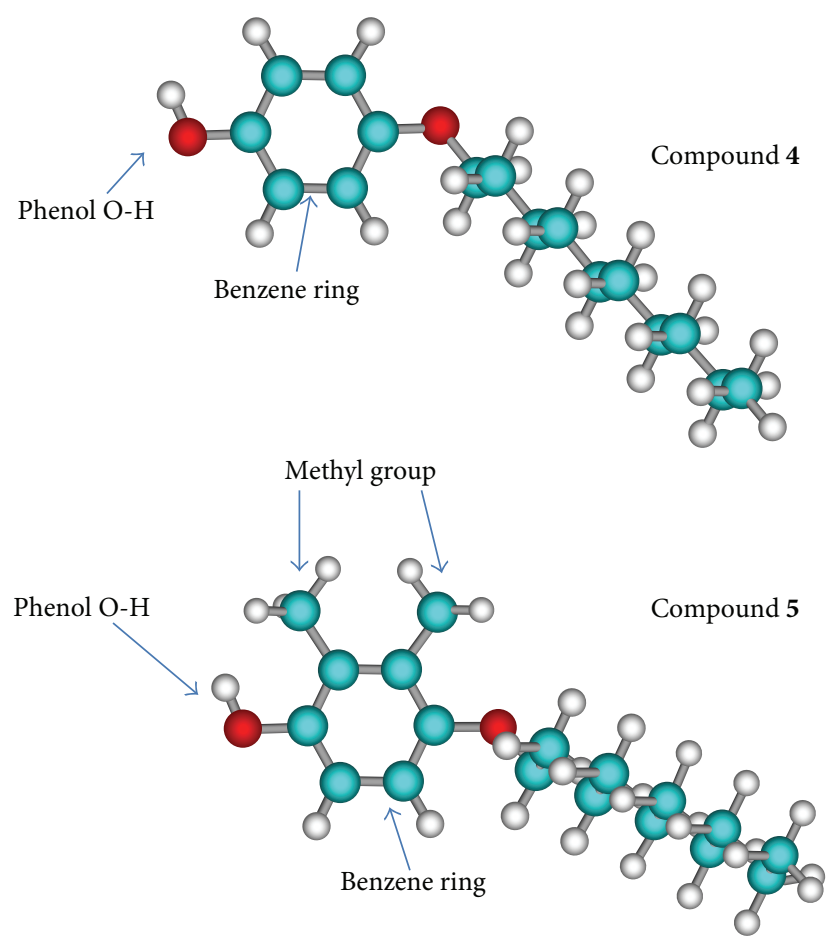

FIGURE 6: Geometry optimized structures of compounds 4 and 5.

bond length $=1.7674 \AA$ ) indicating that the bond weakening in $\mathbf{2}$ is a steric effect from the ortho methyl group. While placing two ortho methyl groups on compound 1 (i.e., compound 3) does not result in significant additional melting point depression (relative to 2), it significantly weakens the intermolecular head-to-head hydrogen bond (calculated hydrogen bond length $=1.7769 \AA$ ) and disrupts molecular packing in the homodimer resulting in loss of all LC phases. Intermolecular head-to-head hydrogen bonding in phenols is much weaker than in acids; therefore, the melting points of phenols $\mathbf{4}$ and $\mathbf{5}$ are unaffected by the addition of methyl lateral substituents. While stilbazole 6 has a smectic B LC 

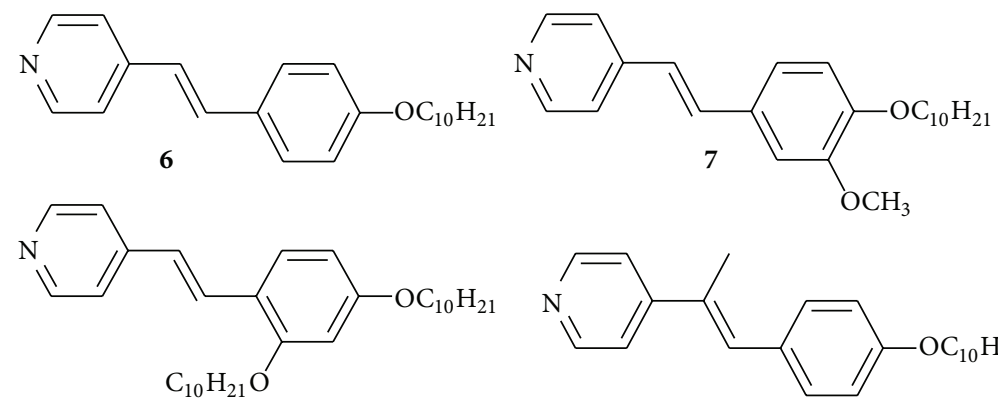

8

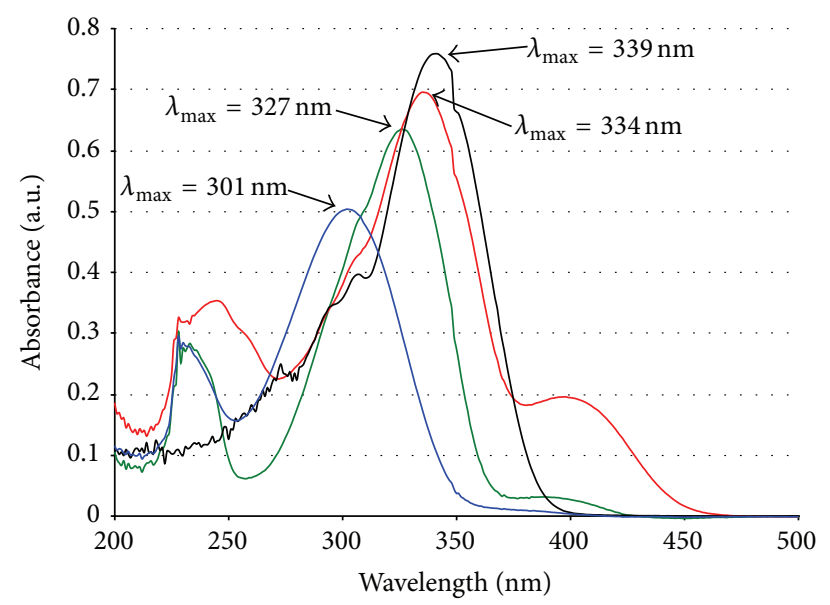

-6
-7

FIGURE 7: UV-VIS spectra of stilbazoles 6-9 in dichloromethane.
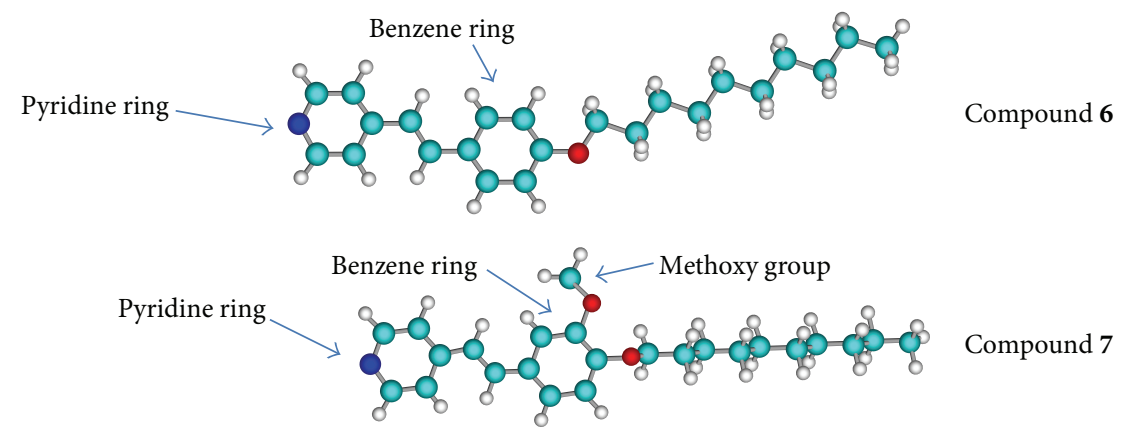

Pyridine ring

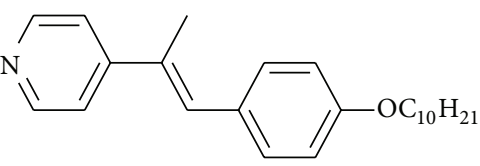

9 


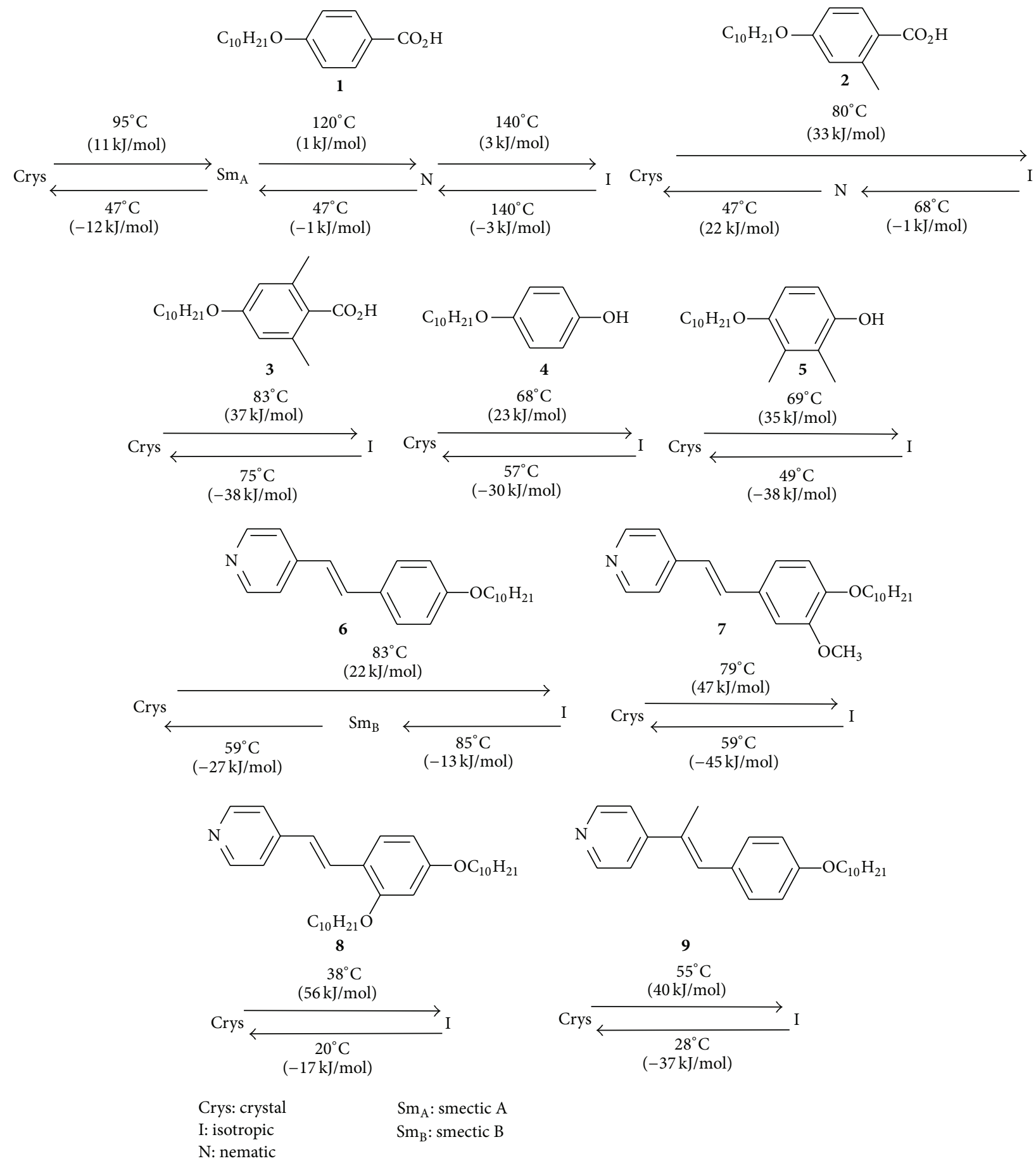

Figure 9: Phase transitions of compounds 1-9.

phase, placing lateral substituents on the stilbazole results in complete loss of LC phases due to disruption of molecular packing in the LC state.

Using FTIR, we have previously demonstrated that, when mixed together, our model compounds participate in strong intermolecular donor-acceptor hydrogen bonding forming hydrogen bonded heterodimers [36]. The phase transitions of several 1:1 (mol : mol, donor : acceptor) mixtures of compounds 1-9 are shown in Figure 11. POM (polarized optical microscopy) images of the liquid phases of 2, 6, model mixture A, and model mixture B are shown in Figure 12. While model mixtures A and B have enantiotropic LC phases, none of the other mixtures in Figure 11 possess LC phases. Model mixture $\mathrm{C}$ has a significantly lower melting point than 

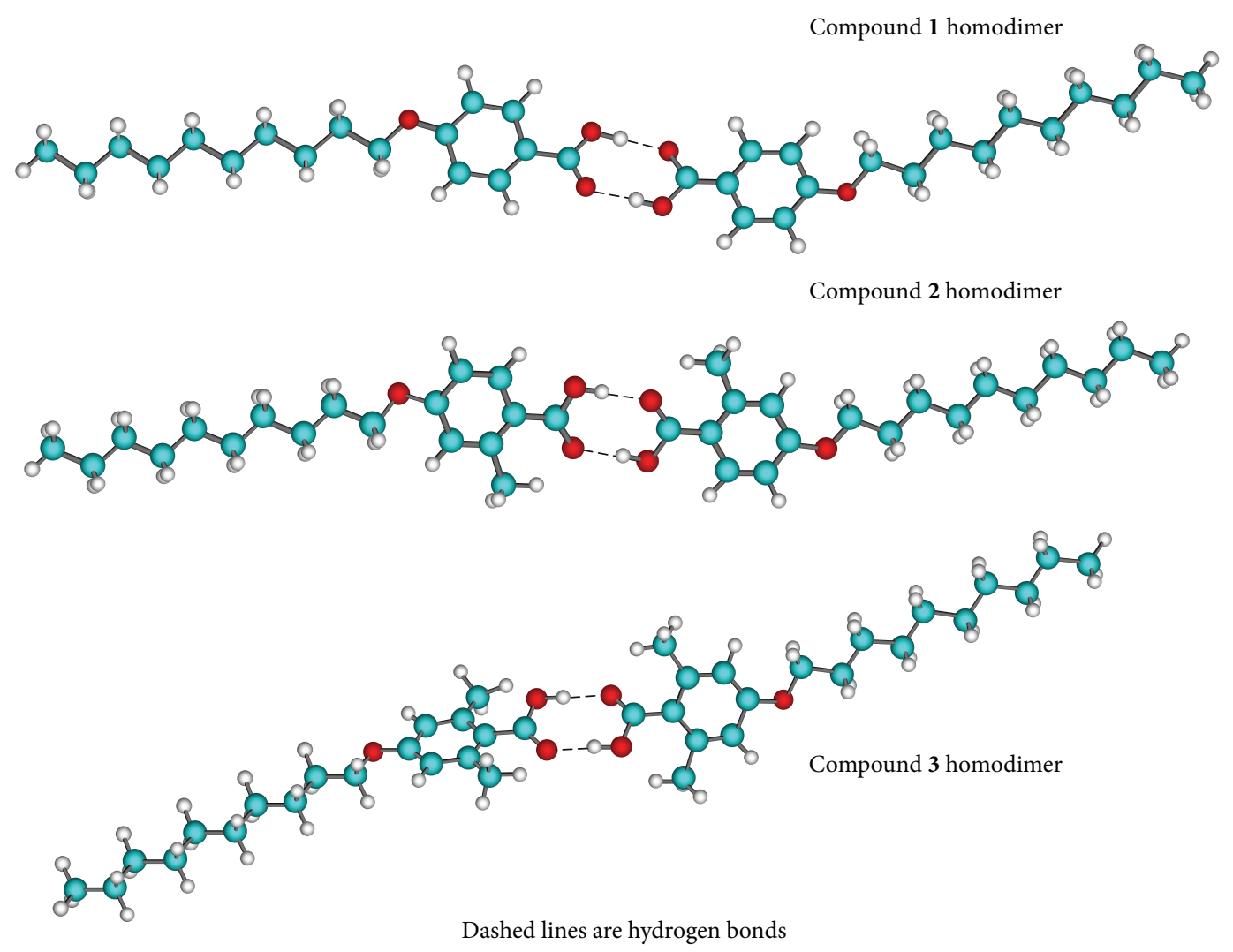

Figure 10: Molecular modeling of acids 1-3.

model mixture $\mathrm{B}$, in contrast to the observations for acid homodimers 2 and 3 , suggesting the two ortho methyl groups significantly disrupt molecular packing in model mixture C. Despite the similar geometries of compounds 6 and 7, mixtures $\mathrm{D}$ and $\mathrm{E}$ (which incorporate 7 ) phase separate and do not have any LC phases indicating the molecular packing, and intermolecular donor-acceptor hydrogen bonding is sensitive to the methoxy substituent on the stilbazole. Model mixtures $F$ and $G$ form glass upon cooling which can be attributed to poor packing of molecules in the solid state as a result of the extra decyloxy substituent. Despite the inhibition of packing by the extra decyloxy substituent, the melting point of model mixture $G$ is much lower than that of F suggesting that the ortho methyl substituent plays a significant role in disruption of molecular packing in mixture G. Like mixtures $\mathrm{D}$ and $\mathrm{E}$, stilbazole 9 containing mixtures $\mathrm{H}$ and $\mathrm{I}$ does not contain any LC phase which can be attributed to disruption of intermolecular donor-acceptor hydrogen bonding and packing in the solid state due to stilbazole ring twisting. The melting points of model mixtures $\mathrm{H}$ and I are identical, suggesting the disruption in packing is almost entirely the result of stilbazole ring twisting. Lateral substitution on the phenol ring in mixture $\mathrm{K}$ results in a significant melting point depression (relative to J); however, unlike mixture $\mathrm{A}$, the weaker phenol-stilbazole hydrogen bond $[56,57]$ in mixture $\mathrm{J}$ cannot form the rigid mesogenic core required to form a calamatic hydrogen bonded liquid crystal. Lateral substitution still disrupts intermolecular donor-acceptor hydrogen bonding in mixture $\mathrm{K}$, resulting in a significant melting point depression relative to that in mixture J.

\section{Conclusions}

The preparation and characterization of a series of laterally substituted benzoic acids, phenols, and stilbazoles are reported. Placing two methyl groups ortho to the acid functionality in benzoic acid molecules twists the $\mathrm{C}=\mathrm{O}$ out of the plane of the benzene ring and thus reduces conjugation between the benzene ring and $\mathrm{C}=\mathrm{O}$. While the electronics of phenol rings is not sensitive to methyl lateral substation, the electronics of the stilbazole unit is very sensitive to lateral substation. The differences in the melting point and phase transitions upon lateral substitution are due to steric effects on the intermolecular hydrogen bonding and packing of molecules in the solid state. While lateral substitution lowers the melting point of the model compounds, in most cases, the lateral substituent results in the loss of LC phases.

\section{Conflict of Interests}

The author declares that there is no conflict of interests regarding the publication of this paper. 


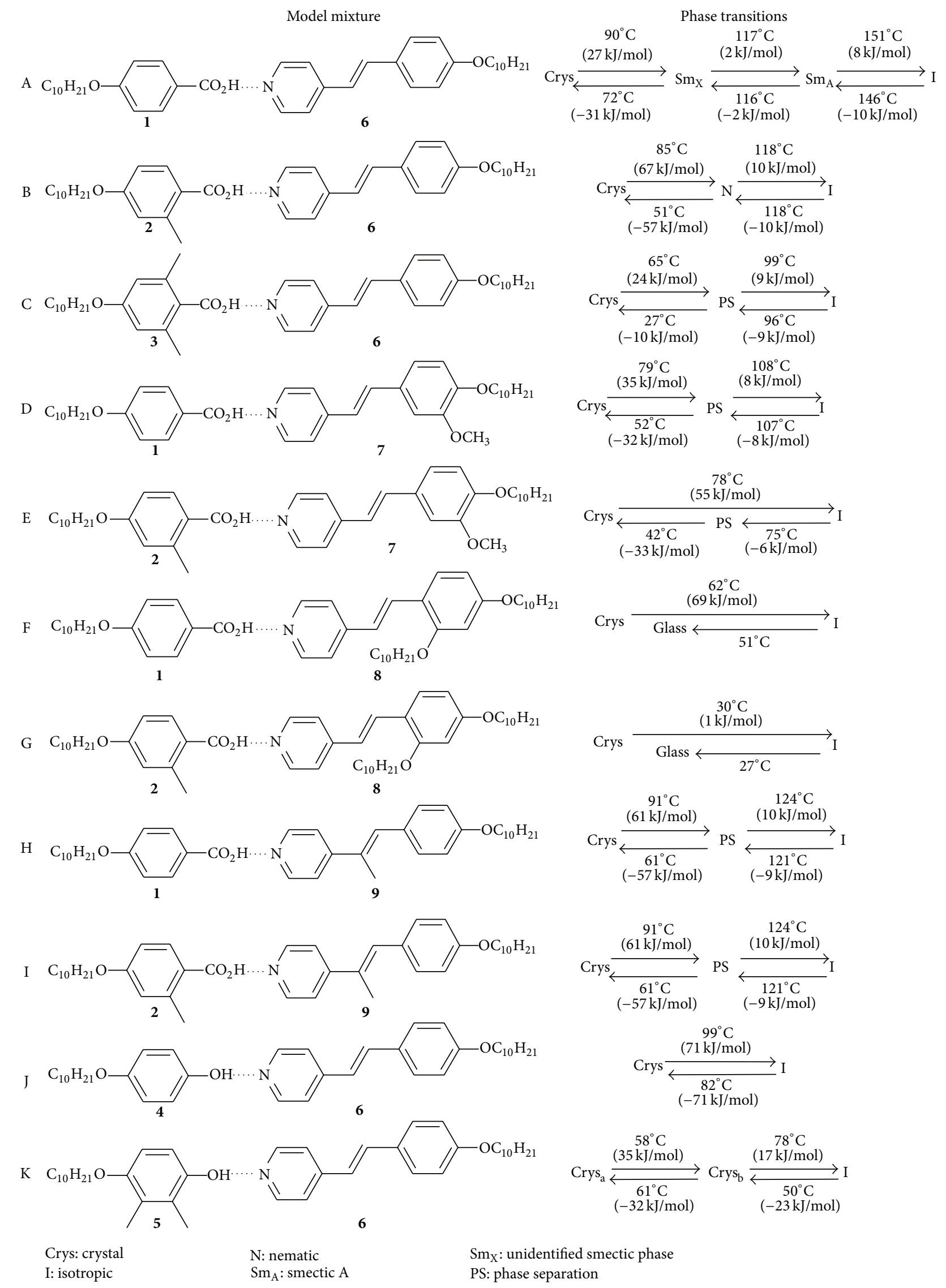

FIGURE 11: Phase transitions of hydrogen bonded heterodimers made from compounds 1-9. 


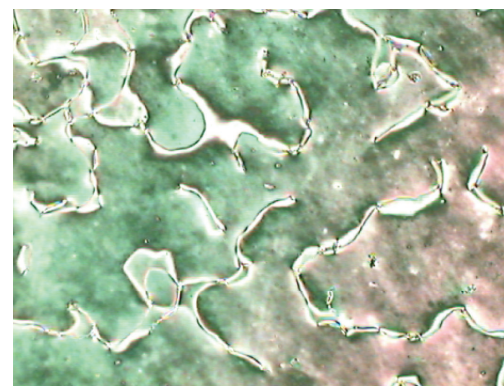

Nematic phase of 2 at $65^{\circ} \mathrm{C}$

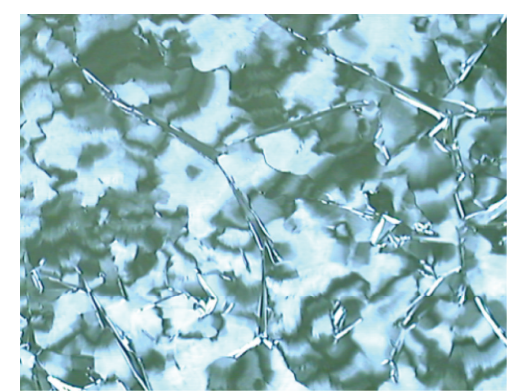

$\mathrm{S}_{\mathrm{B}}$ phase of 6 at $80^{\circ} \mathrm{C}$

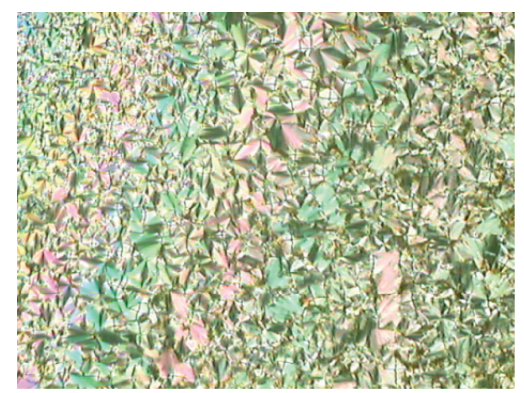

$\mathrm{S}_{\mathrm{X}}$ phase of mixture A at $90^{\circ} \mathrm{C}$ (cooling cycle)

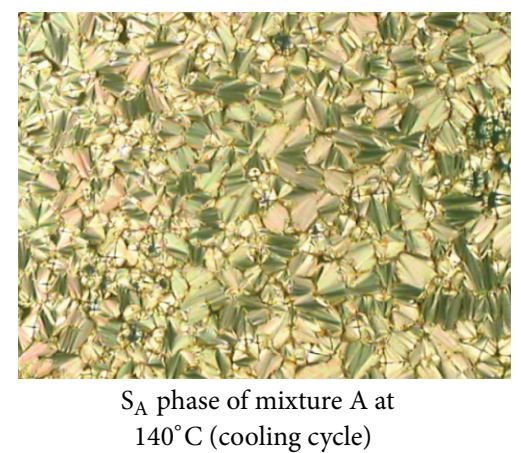

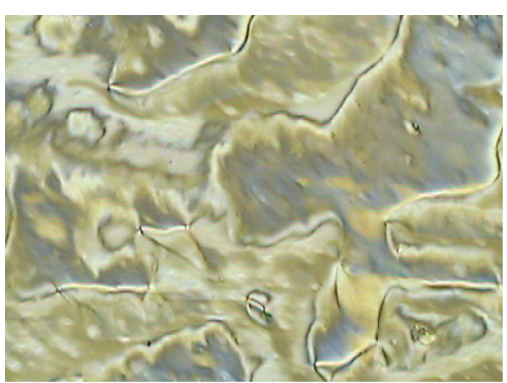

Nematic schlieren texture of mixture $\mathrm{B}$ at $59^{\circ} \mathrm{C}$ (cooling cycle)

FIGURE 12: Polarized optical microscopy (POM) images of liquid crystalline phases in model compounds and mixtures.

\section{Acknowledgments}

The author would like to thank the National Science Foundation under Grant CHE_0094195, Oak Ridge Associated Universities, the Materials Technology Center at Southern Illinois University, Carbondale, and the Office of Research Development and Administration at Southern Illinois University for support of this research.

\section{References}

[1] M. Wesolowski and T. Konarski, "Studies on the thermal decomposition of benzoic acid and its derivatives," Journal of Thermal Analysis and Calorimetry, vol. 55, no. 3, pp. 995-1002, 1999.

[2] C. R. Kaiser, E. A. Basso, and R. Rittner, "Substituent-induced ${ }^{13} \mathrm{C}$ chemical shifts of 3-substituted camphors," Magnetic Resonance in Chemistry, vol. 39, no. 10, pp. 643-644, 2001.

[3] J. Ohshita, H. Kai, A. Takata et al., "Effects of conjugated substituents on the optical, electrochemical, and electron-transporting properties of dithienosiloles," Organometallics, vol. 20, no. 23 , pp. 4800-4805, 2001.

[4] T. H. Lowry and K. S. Richardson, Mechanism and Theory in Organic Chemistry, HarperCollins, New York, NY, USA, 3rd edition, 1987.

[5] J. G. Hoggett, R. B. Moodie, J. R. Penton, and K. Schofield, Nitration and Aromatic Reactivity, Cambridge University Press, Cambridge, UK, 1971.

[6] B. Galabov, S. Ilieva, and H. F. Schaefer III, "An efficient computational approach for the evaluation of substituent constants," Journal of Organic Chemistry, vol. 71, no. 17, pp. 6382-6387, 2006.
[7] M. B. Smith and J. March, March's Advanced Organic Chemistry: Reactions, Mechanisms, and Structure, Wiley, New York, NY, USA, 2013.

[8] C. Hansch, A. Leo, and R. W. Taft, "A survey of hammett substituent constants and resonance and field parameters," Chemical Reviews, vol. 91, no. 2, pp. 165-195, 1991.

[9] K. N. Houk, R. J. Loncharich, J. F. Blake, and W. L. Jorgensen, "Substituent effects and transition structures for Diels-Alder reactions of butadiene and cyclopentadiene with cyanoalkenes," Journal of the American Chemical Society, vol. 111, no. 26, pp. 9172-9176, 1989.

[10] C. Schmidt, "Substituent effects on the orientation of DielsAlder reactions. I," Journal of Organic Chemistry, vol. 35, no. 5, pp. 1324-1328, 1970.

[11] R. Sustmann, "A simple model for substituent effects in cycloaddition reactions. II. The diels-alder reaction," Tetrahedron Letters, vol. 12, no. 29, pp. 2721-2724, 1971.

[12] B. J. McNelis, D. D. Sternbach, and A. T. MacPhail, "Synthetic and kinetic studies of substituent effects in the furan intramolecular Diels-Alder reaction," Tetrahedron, vol. 50, no. 23, pp. 6767-6782, 1994.

[13] M. M. Díaz-Requejo, P. J. Pérez, M. Brookhart, and J. L. Templeton, "Substituent effects on the reaction rates of copper-catalyzed cyclopropanation and aziridination of parasubstituted styrenes," Organometallics, vol. 16, no. 20, pp. 43994402, 1997.

[14] A. Shafir and S. L. Buchwald, "Highly selective roomtemperature copper-catalyzed C-N coupling reactions," Journal of the American Chemical Society, vol. 128, no. 27, pp. 8742-8743, 2006.

[15] P. S. Herradura, K. A. Pendola, and R. K. Guy, "Coppermediated cross-coupling of aryl boronic acids and alkyl thiols," Organic Letters, vol. 2, no. 14, pp. 2019-2022, 2000. 
[16] K. Heuzé, D. Méry, D. Gauss, J.-C. Blais, and D. Astruc, "Copper-free monomeric and dendritic palladium catalysts for the sonogashira reaction: substituent effects, synthetic applications, and the recovery and re-use of the catalysts," ChemistryA European Journal, vol. 10, no. 16, pp. 3936-3944, 2004.

[17] D. A. Evans, S. J. Miller, T. Lectka, and P. von Matt, "Chiral bis(oxazoline)copper(II) complexes as lewis acid catalysts for the enantioselective Diels-Alder reaction," Journal of the American Chemical Society, vol. 121, no. 33, pp. 7559-7573, 1999.

[18] K. B. Wiberg, "Substituent effects on the acidity of weak acids. 1. Bicyclo[2.2.2] octane-1-carboxylic acids and bicyclo[1.1.1]pentane-1-carboxylic acids," Journal of Organic Chemistry, vol. 67, no. 5, pp. 1613-1617, 2002.

[19] C.-T. Chen and J. S. Siegel, "Through-space polar-.pi. effects on the acidity and hydrogen-bonding capacity of carboxylic acids," Journal of the American Chemical Society, vol. 116, no. 13, pp. 5959-5960, 1994.

[20] M. R. F. Siggel, A. Streitwieser Jr., and T. D. Thomas, "The role of resonance and inductive effects in the acidity of carboxylic acids," Journal of the American Chemical Society, vol. 110, no. 24, pp. 8022-8028, 1988.

[21] R. D. Topsom, "The nature and analysis of substituent electronic effects," in Progress in Physical Organic Chemistry, R. W. Taft, Ed., Wiley, New York, NY, USA, 2009.

[22] F. G. Bordwell and J.-P. Cheng, "Substituent effects on the stabilities of phenoxyl radicals and the acidities of phenoxyl radical cations," Journal of the American Chemical Society, vol. 113, no. 5, pp. 1736-1743, 1991.

[23] T. B. McMahon and P. Kebarle, "Intrinsic acidities of substituted phenols and benzoic acids determined by gas-phase protontransfer equilibriums," Journal of the American Chemical Society, vol. 99, no. 7, pp. 2222-2230, 1977.

[24] R. Vianello and Z. B. Maksić, "Triadic analysis of substituent effects-gas-phase acidity of para-substituted phenols," Tetrahedron, vol. 62, no. 14, pp. 3402-3411, 2006.

[25] A. Pross, L. Radom, and R. W. Taft, "Theoretical approach to substituent effects. Phenols and phenoxide ions," Journal of Organic Chemistry, vol. 45, no. 5, pp. 818-826, 1980.

[26] F. G. Bordwell, R. J. McCallum, and W. N. Olmstead, "Acidities and hydrogen bonding of phenols in dimethyl sulfoxide," Journal of Organic Chemistry, vol. 49, no. 8, pp. 1424-1427, 1984.

[27] M. D. Joesten and L. J. Schaad, Hydrogen Bonding, Marcel Dekker, New York, NY, USA, 1974.

[28] A. Burawoy, "Effect of hydrogen bond formation on the electronic spectra of phenolic substances," in Hydrogen Bonding, D. Hadži, Ed., Pergamon Press, London, UK, 1959.

[29] A. Reiser, "Effect of structure and ring substitution on the hydrogen bond in oximes," in Hydrogen Bonding, D. Hadži, Ed., Pergamon Press, London, UK, 1959.

[30] S. N. Vinogradov and R. H. Linnell, Hydrogen Bonding, Litton Educational, New York, NY, USA, 1971.

[31] Z. Dega-Szafran, E. Dulewicz, and M. Szafran, "Spectroscopic studies of $N$-methylpiperidine betaine complexes with phenols," Journal of Molecular Structure, vol. 704, no. 1-3, pp. 155161, 2004.

[32] N. Seurre, K. L. Barbu-Debus, F. Lahmani, A. ZehnackerRentien, and J. Sepiol, "Structural study of hydrogen-bonded complexes between 2-aminoethanol derivatives and a chiral aromatic alcohol," Journal of Molecular Structure, vol. 692, no. 1-3, pp. 127-137, 2004.
[33] C. Landorf, J. Wolf, C. Li et al., "Design of polar organic liquid crystalline thin films," in Proceedings of the Organic Thin Films for Photonic Applications; Trends in Optics and Photonics Series, Optical Society of America, Long Beach, Calif, USA, 2001.

[34] C. Landorf, J. Simpson, J. Jacobsen, and D. J. Dyer, "Design and synthesis of non-centrosymmetric organic thin films with hydrogen bonded main chain polymers," Polymeric Materials: Science and Engineering, vol. 83, pp. 172-173, 2000.

[35] D. J. Dyer, J. Wolf, C. Li et al., "Design and synthesis of noncentrosymmetric hydrogen bonded main chain liquid crystalline polymers: towards polar order in organic thin films," Polymer Preprints, vol. 44, p. 578, 2003.

[36] J. R. Wolf, T. Zhao, C. Landorf, and D. J. Dyer, "Synthesis and characterisation of laterally substituted noncentrosymmetric main chain hydrogen-bonded polymers," Liquid Crystals, vol. 41, no. 5, pp. 721-730, 2014.

[37] J. R. Wolf, "Main chain noncentrosymmetric hydrogen bonded macromolecules incorporating aniline, alkanol, and alkanoic acid hydrogen bond donors," Journal of Polymers, vol. 2014, Article ID 472901, 7 pages, 2014.

[38] D. J. Dyer and J. R. Wolf, "Synthesis and characterization of noncentrosymmetric main chain hydrogen bonded macromolecules incorporating an azo-stilbazole acceptor," Macromolecular Research, vol. 22, no. 8, pp. 870-874, 2014.

[39] D. J. Dyer and J. R. Wolf, "Synthesis and characterization of noncentrosymmetric main chain hydrogen bonded macromolecules incorporating a 4-pyridone hydrogen bond acceptor," Macromolecular Research, vol. 22, no. 6, pp. 664-668, 2014.

[40] S. Chandrasekhar, Liquid Crystals, Cambridge University, Cambridge, UK, 1977.

[41] T. Kato, N. Mizoshita, and K. Kanie, "Hydrogen-bonded liquid crystalline materials: supramolecular polymeric assembly and the induction of dynamic function," Macromolecular Rapid Communications, vol. 22, no. 11, pp. 797-814, 2001.

[42] C. S. Hsu, K. F. Shyu, Y. Y. Chuang, and S.-T. Wu, "Synthesis of laterally substituted bistolane liquid crystals," Liquid Crystals, vol. 27, no. 2, pp. 283-287, 2000.

[43] S. Greenfield, D. Coates, E. Brown, and R. Hittich, "Laterally fluorinated tolanes of low melting point," Liquid Crystals, vol. 13, no. 2, pp. 301-305, 1993.

[44] K. Liu, H. Li, K. Wang, and J. Wen, "Synthesis and characterization of novel fluorinated bistolane-type liquid crystals," Liquid Crystals, vol. 28, no. 10, pp. 1463-1467, 2001.

[45] M. E. Neubert, S. S. Keast, Y. Dixon-Polverin et al., "The effect of 2- and 3-lateral substituents on the acid side of 4,4' disubstituted phenylbenzoates and phenylthiobenzoates on mesomorphic properties," Molecular Crystals and Liquid Crystals Science and Technology Section A: Molecular Crystals and Liquid Crystals, vol. 250, no. 1, pp. 109-123, 1994.

[46] H. Okamoto, J. Wu, Y. Morita, and S. Takenaka, "Synthesis of 4-alkoxy-2-substituted-benzenethiols and their application to thermotropic liquid crystals," Bulletin of the Chemical Society of Japan, vol. 75, no. 1, pp. 175-179, 2002.

[47] S. Connolly, C. Bennion, S. Botterell et al., "Design and synthesis of a novel and potent series of inhibitors of cytosolic phospholipase $\mathrm{A}_{2}$ based on a 1,3-disubstituted propan-2-one skeleton," Journal of Medicinal Chemistry, vol. 45, no. 6, pp. 1348-1362, 2002.

[48] J. D. Bunning and J. E. Lydon, "Crystal structure of $p$-ndecyloxybenzoic acid," Journal of the Chemical Society, Perkin Transactions 2, vol. 2, no. 12, pp. 1621-1626, 1979. 
[49] M. Colapietro and A. Domenicano, "Structural studies of benzene derivatives. IV. Refinement of the crystal structure of p-methoxybenzoic acid," Acta Crystallographica Section B Structural Crystallography and Crystal Chemistry, vol. 34, no. 11, pp. 3277-3280, 1978.

[50] R. Fausto, A. Matos-Beja, and J. A. Paixão, "Molecular structure and charge density analysis of $p$-methoxybenzoic acid (anisic acid)," Journal of Molecular Structure, vol. 435, no. 3, pp. 207218, 1997.

[51] F. Florencio and P. Smith-Verdier, "The crystal structure of 2,4,6-trimethylbenzoic acid," Acta Crystallographica B, vol. 26, no. 6, pp. 659-666, 1970.

[52] M. Klessinger, "Pariser-parr-pople-rechnungen an molekülen mit aminogruppen," Theoretica Chimica Acta, vol. 5, no. 3, pp. 251-265, 1966.

[53] K. Vikram, N. Tarcea, J. Popp, and R. K. Singh, “Temperaturedependent raman study of the smectic to nematic phase transition and vibrational analysis using density functional theory of the liquid crystalline system 4-decyloxy benzoic acid," Applied Spectroscopy, vol. 64, no. 2, pp. 187-194, 2010.

[54] K. Gayathri, S. Balamurugan, and P. Kannan, "Self-assembly of azobenzene based side-chain liquid crystalline polymer and $n$ alkyloxybenzoic acids," Journal of Chemical Sciences, vol. 123, no. 3, pp. 255-263, 2011.

[55] L. Jongen, B. Goderis, I. Dolbnya, and K. Binnemans, "Influence of the chain length on the thermal behavior of lanthanide(III) 4alkoxybenzoates," Chemistry of Materials, vol. 15, no. 1, pp. 212217, 2003.

[56] T. Koga, H. Ohba, A. Takase, and S. Sakagami, "Liquid crystalline phases through intennolecular hydrogen bonding formed in a mixture of phenol derivatives and 4, $4^{\prime}$-bipyridine," Chemistry Letters, vol. 11, pp. 2071-2074, 1994.

[57] D. J. Price, K. Willis, T. Richardson, G. Ungar, and D. W. Bruce, "Hydrogen bonded liquid crystals from nitrophenols and alkoxystilbazoles," Journal of Materials Chemistry, vol. 7, no. 6, pp. 883-891, 1997. 

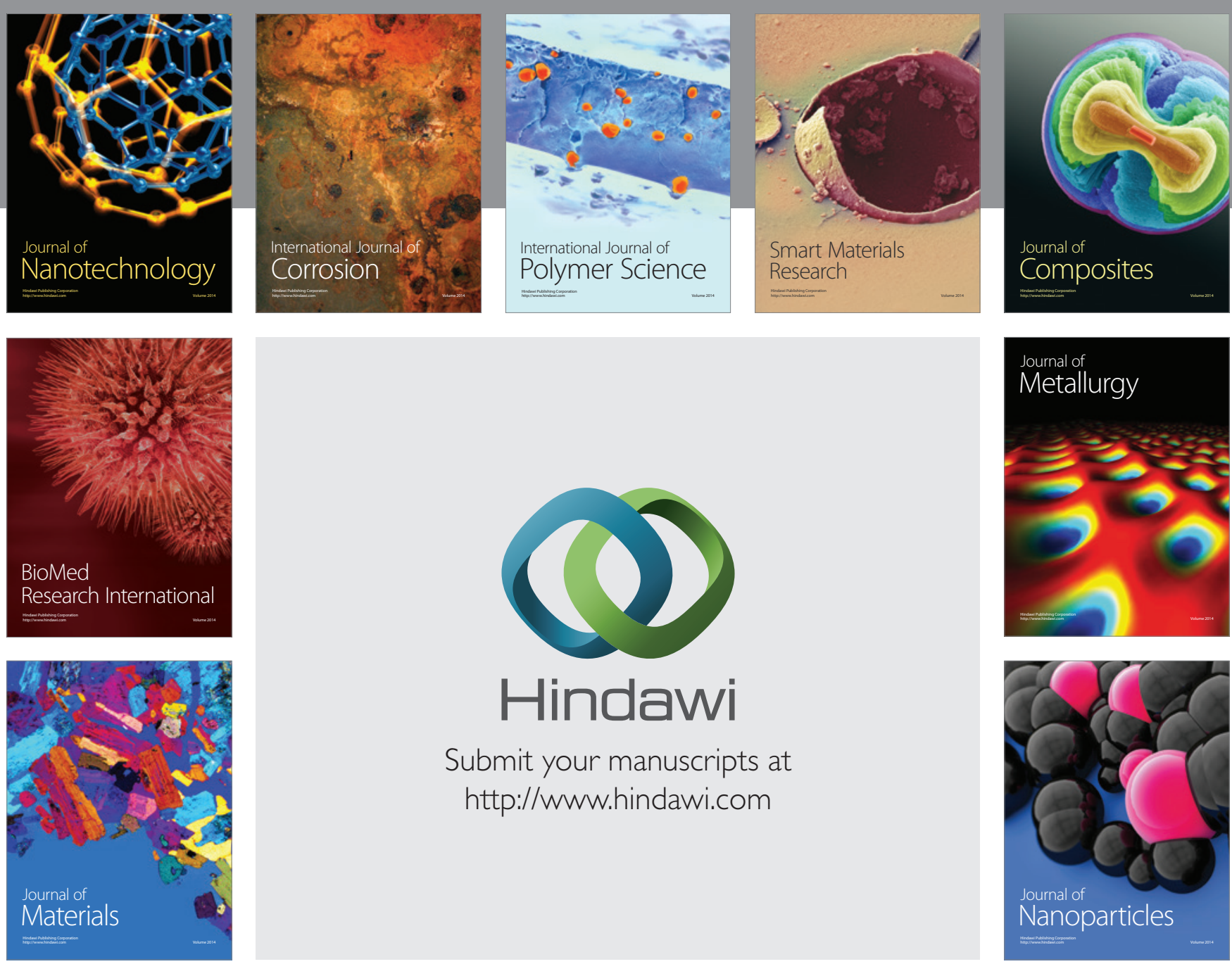

Submit your manuscripts at http://www.hindawi.com
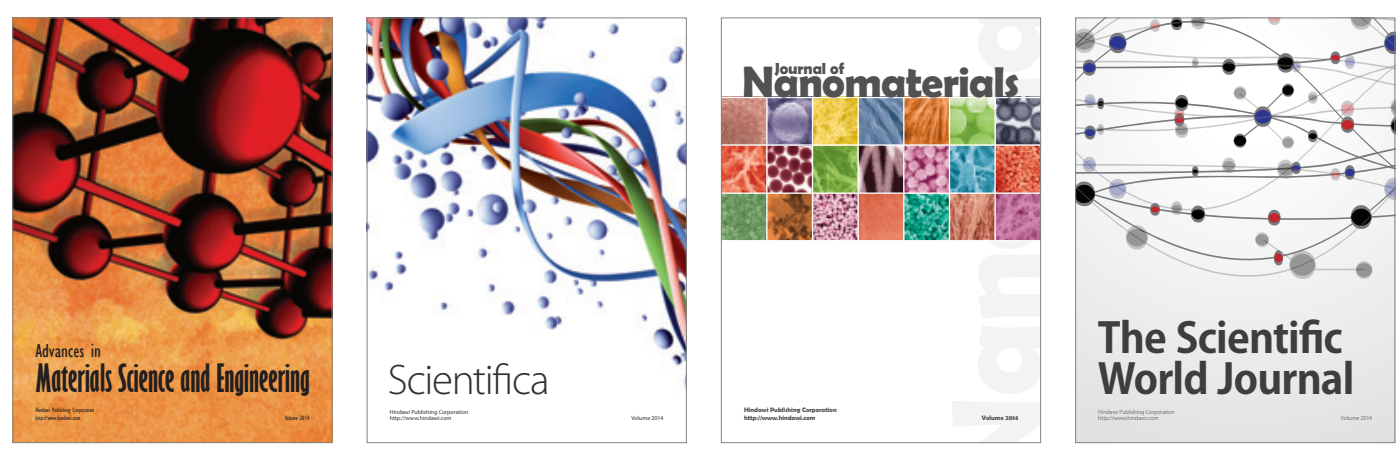

\section{The Scientific World Journal}
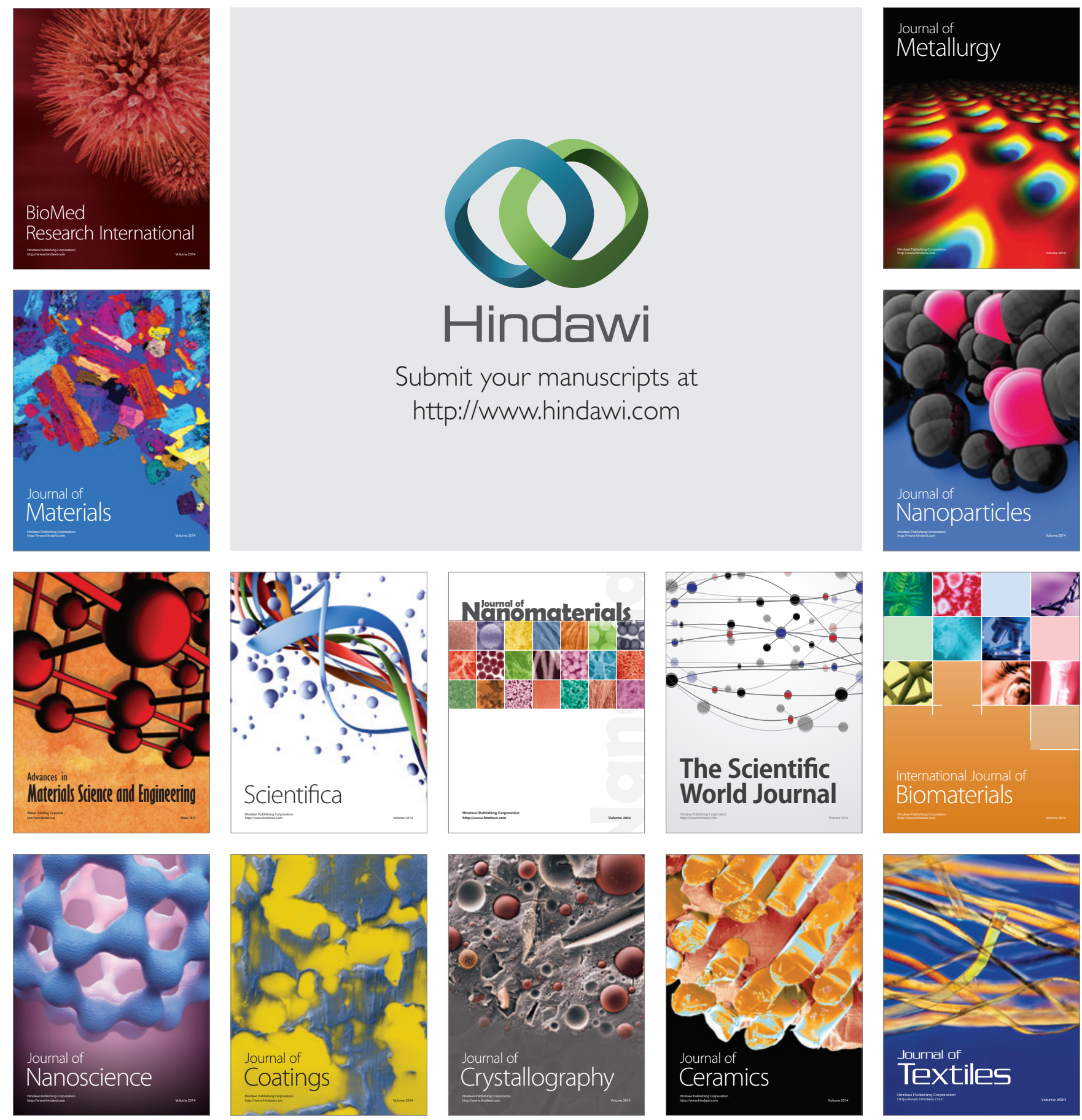